\title{
Immunization of cultured juvenile rockfish Sebastes schlegeli against Microcotyle sebastis (Monogenea)
}

\author{
Ki Hong Kim*, Yoon Jung Hwang, Jae Bum Cho, Soo Il Park \\ Department of Aquatic Life Medicine, College of Fisheries Science, Pukyong National University, Pusan 608-737, Korea
}

\begin{abstract}
To determine whether immunization with Microcotyle sebastis antigen could induce protection against the parasite's establishment, naive juvenile rockfish were immunized by injection or immersion with whole worm antigen of $M$. sebastis. The infestation intensities of immunized groups following a challenge ( $2 \mathrm{wk}$ after boosting) with $5000 \mathrm{M}$. sebastis eyed-eggs were significantly lower than those of control groups, when determined $7 \mathrm{wk}$ postinfection. The fish in the groups boosted with $M$. sebastis antigen showed stronger protection than unboosted groups. The control group injected with FCA only showed a significantly smaller number of worms than the control group, which was immersed in PBS containing seawater. The results strongly suggest that both specific and nonspecific immune factors participate in the protection of rockfish against $M$. sebastis establishment.
\end{abstract}

KEY WORDS: Rockfish · Microcotyle sebastis - Immunization · Injection · Immersion

\section{INTRODUCTION}

Production of rockfish Sebastes schlegeli from aquaculture has increased rapidly over the past decade, and this fish has become the second most important marine cultured fish in Korea. One problem associated with rockfish farming in Korea is infestation with the gill monogenean parasite Microcotyle sebastis, which causes extensive mortalities of juvenile rockfish every year. Recently, Kim \& Choi (1998) and Kim et al. (1998) reported on the effective treatment measures against $M$. sebastis infestation in cultured rockfish by oral administration of various chemotherapeutics. However, little is known on the acquired immunity of fish against this blood-sucking polyopisthocotylean.

Since the first reports of acquired protection in fish against monogenean reinfections (Jahn \& Kuhn 1932, Nigrelli \& Breder 1934) were made, several studies on this topic have been conducted (Lester \& Adams 1974, Scott \& Robinson 1984, Scott 1985, Buchmann 1993, Bondad-Reantaso et al. 1995, Richards \& Chubb 1996). In this study, to determine whether immunization with Microcotyle sebastis antigen could induce protection

•E-mail:khkim@dolphin.pknu.ac.kr against the parasite's establishment, naive juvenile rockfish were immunized by injection or immersion with whole worm antigen of $M$. sebastis. The infestation intensity, following a challenge with 5000 eyedeggs, was used as a parameter of protection against $M$. sebastis infestation.

\section{MATERIALS AND METHODS}

Fish. Fingerling rockfish were obtained from a hatchery in Tongyoung, Korea, and determined to be free of infestation with Microcotyle sebastis after examining 20 fish out of 100 fish. The fish were maintained in a flow-through seawater aquarium at $18 \pm 1^{\circ} \mathrm{C}$ for 3 mo prior to the experiment. Fish were fed $1 \%$ body weight daily with a commercial pellet ration.

Preparation of antigen. Thousands of Microcatyle sebastis adult worms were collected from heavily infected rockfish which were cultured in several local farms. The parasites were washed with phosphate buffered saline (PBS), homogenized by sonicating for $3 \mathrm{~min}$ in an ultrasonic processor, diluted with PBS, and filtered through a $0.45 \mu \mathrm{m}$ syringe filter. Protein concentration of the antigen extract was estimated using 
the Bradford protein-dye binding assay (Bradford 1976) and adjusted to a final protein concentration of $15 \mathrm{mg} \mathrm{ml}$.

Immunization of fish. The naive juvenile rockfish (body weight: 8 to $10 \mathrm{~g})$ were separated randomly into 6 groups of 10 individuals and maintained in $50 \mathrm{l}$ tanks. Each fish in Group 1 was injected intraperitoneally (i.p.) with $0.025 \mathrm{ml}$ of the prepared antigen emulsified in an equal volume of Freund's complete adjuvant (FCA) and boosted with an i.p. injection of $0.05 \mathrm{ml}$ antigen after 2 wk. Group 2 differed from Group 1 as it was only boosted with PBS. Group 3 was used as a control for injection immunization, and each fish was injected i.p. with $0.025 \mathrm{ml}$ PBS and an equal amount of FCA. This group was boosted with an injection of $0.05 \mathrm{ml}$ PBS after $2 \mathrm{wk}$. The fish in Group 4 were immunized by immersion for $10 \mathrm{~min}$, twice at $2 \mathrm{wk}$ intervals, in a vessel containing $600 \mathrm{ml}$ of seawater and $6 \mathrm{ml}$ of the above antigen. Group 5 differed from Group 4 as it was boosted with $1 \%$ PBS containing seawater. Group 6 was used as a control for immersion immunization, and fish were immersed twice in $1 \%$ PBS containing seawater for $10 \mathrm{~min}$ at $2 \mathrm{wk}$ intervals.

Collection of Microcotyle sebastis eggs. The water containing rockfish heavily infested with Microcotyle sebastis was filtered through Müller gauze (pore size: $100 \mu \mathrm{m}$ ). Eggs entangled in the gauze were separated under a stereomicroscope, placed in a vessel containing seawater filtered through ultrafiltration disk membranes (Sigma) and incubated for $7 \mathrm{~d}$ at $20^{\circ} \mathrm{C}$. The maturity of eggs was confirmed microscopically, and only eyed-eggs were used in the challenge experiment.

Challenge procedure. Two weeks after the booster, fish in each group were exposed for $7 \mathrm{~d}$ to 5000 eyed-

Table 1. The values of significance among experimental groups calculated using Mann-Whitney's $U$-test. See Fig. 1 legend for group definitions

\begin{tabular}{|lcccccc|}
\hline $\begin{array}{l}\text { Experi- } \\
\text { mental } \\
\text { group }\end{array}$ & 1 & 2 & 3 & 4 & 5 & 6 \\
\hline 1 & - & 0.000 & 0.000 & 0.000 & 0.000 & 0.000 \\
2 & & - & 0.014 & 0.113 & 0.006 & 0.000 \\
3 & & & - & 0.212 & 0.536 & 0.004 \\
4 & & & & - & 0.086 & 0.000 \\
5 & & & & & - & 0.036 \\
\hline
\end{tabular}

eggs of Microcotyle sebastis. To prevent loss of eggs before hatching, the water of each tank was only aerated and not changed during the infection period. After $7 \mathrm{wk}$ of infection, all fish in each group were examined for parasites. All worms recovered from the gills of each fish were counted under a stereomicroscope.

Statistical analysis. All data were analyzed using Mann-Whitney's $U$-test (SPSS 7.5 for Windows, SPSS Inc.).

\section{RESULTS}

The results (Fig. 1, Table 1) show that the infestation intensities of immunized groups following a challenge with 5000 Microcotyle sebastis eyed-eggs were significantly lower than those of control groups. The established numbers of $M$. sebastis on the fish in Groups 1 and 2 were significantly $(p<0.01)$ smaller than those on the fish in Groups 4 and 5, respectively. The groups boosted with $M$. sebastis antigen (Groups 1 and 4) showed higher protection against $M$. sebastis establishment than the unboosted groups (Groups 2 and 5). Furthermore, the number of parasites that established on the fish in Group 3 (a control for injection immunization) was significantly $(p<0.01)$ lower than that on the fish in Group 6 (a control for immersion immunization). 


\section{DISCUSSION}

The results of this study demonstrate for the first time that rockfish acquire partial protection against Microcotyle sebastis by both routes of antigen administration, i.p. injection and immersion, and strongly suggest that both specific and nonspecific immune factors participate in the protection against $M$. sebastis infestation. Although the acquired protection of fish against reinfection of monogenean parasites has been reported by some authors (Vladimirov 1971, Lester \& Adams 1974, Scott \& Robinson 1984, Scott 1985), there are no reports on the acquired protection against blood-sucking polyopisthocotyleans.

Bondad-Reantaso et al. (1995) reported that the primed Japanese flounder, which had been exposed to eyed-eggs of Neobenedenia girellae and subjected to a 10 min freshwater treatment $10 \mathrm{~d}$ postinfection, showed a significantly lower number of $N$. girellae infestation than control fish when challenged with eyed-eggs of $N$. girellae. They suggested that serum antibody had no involvement in the acquired protection against $N$. girellae based on the result of no significant difference in the parasite counts between antigen-injected and PBS-injected fish. Lester (1972) also reported that intramuscular injections of whole Gyrodactylus alexanderi antigen conferred no protection in threespine sticklebacks. In contrast to those reports, the present results demonstrate that vaccination with whole worm antigen injected i.p. provides a significant level of protection against Microcotyle sebastis infestation. The causes of this discrepancy are unclear; however, the difference in feeding habits among monogenean species is thought to be a factor, i.e. gyrodactylids and benedenids are tissue-feeding monogeneans, but $M$. sebastis is a bloodsucking parasite. In the process of blood feeding, the parasite inevitably contacts with or absorbs immunoreactive factors in the serum of immunized fish. This would have an effect on the survival and establishment of $M$. sebastis on the gills of rockfish.

Although we did not analyse the antibody titre against Microcotyle sebastis antigen in the present study, the significant difference $(p<0.01)$ in the intensity of $M$. sebastis between Groups 1 and 2 suggests that boosting with $M$. sebastis antigen has a significantly positive effect in conferring higher protection against $M$. sebastis establishment. The established worm numbers between Groups 4 (boosted with worm antigen by immersion) and 5 (boosted by immersion with only PBS) were not statistically significant ( $p=$ 0.086). However, the intensity was considerably lower in Group 4 than in Group 5. Therefore, in the case of immersion vaccination, boosting with antigen also tended to confer higher protection than boosting without antigen
In the present study, groups vaccinated by injection showed stronger protection against Microcotyle sebastis infestation than groups vaccinated by immersion. This might be the result of the difference in the amount of absorbed antigen between the 2 routes. However, when the intensity of Group 3 (control to injection vaccine) was compared with that of Group 6 (control to immersion vaccine), significantly $(p<0.01)$ lower numbers of worms established in the fish of Group 3 than in Group 6. This result suggests that nonspecific immune factors stimulated by FCA alone are associated with the protection of rockfish against $M$. sebastis infestation. It is well known that FCA can be used not only as a vaccine carrier but also as a stimulant of nonspecific immunity (Anderson 1992, Secombes 1994). The nonspecific immune factors including complement and leucocytes are known to negatively influence the establishment of gyrodactyids (Buchmann 1998, 1999, Harris et a1. 1998, Buchmann \& Bresciani 1999). Buchmann \& Bresciani (1999) reported that Gyrodactylus derjavini survived less than $3 \mathrm{~h}$ when exposed to supernatant from peritoneal macrophages, which were considered to be activated by i.p. injection of squalene, whereas untreated supernatant from non-activated pronephric leucocytes did not show any lethal effect on the parasites within $3 \mathrm{~h}$. Thus, although there are no data on the roles of nonspecific immune factors to polyopisthocotylean parasites, it is possible that the nonspecific immune factors of the fish in Group 3 might be stimulated with an intraperitoneal injection of FCA, and this would participate in the protection against the establishment of $M$. sebastis.

Acknowledgement. This study was supported by a grant from the Ministry of Maritime Affairs and Fisheries, Republic of Korea.

\section{LITERATURE CITED}

Anderson DP (1992) Immunostimulants, adjuvants, and vaccine carriers in fish: applications to aquaculture. Annu Rev Fish Dis 2:281-307

Bondad-Reantaso MG, Ogawa K, Yoshinaga T, Wakabayashi H (1995) Acquired protection against Neobenedenia girellae in Japanese flounder. Fish Pathol 30:233-238

Bradford M (1976) A rapid and sensitive method for the quantification of microgram quantities of protein utilising the principle of protein-dye binding. Anal Biochem 72: $248-254$

Buchmann K (1993) A note on the humoral immune response of infected Anguilla anguilla against the gill monogenean Pseudodactylogyrus bini. Fish Shellfish Immunol 3: $397-399$

Buchmann K (1998) Binding and lethal effect of complement from Oncorhynchus mykiss on Gyrodactylus derjavini (Platyhelminthes: Monogenea). Dis Aquat Org 32: 195-200 
Buchmann K (1999) Immune mechanism in fish skin against monogeneans - a model. Folia Parasitol 46:1-9

Buchmann K, Bresciani J (1999) Rainbow trout leucocyte activity: influence on the ectoparasitic monogenean Gyrodactylus derjavini. Dis Aquat Org 35:13-22

Harris PD, Soleng A, Bakke TA (1998) Killing of Gyrodactylus salaris (Platyhelminthes, Monogenea) mediated by host complement. Parasitology 117:137-143

Jahn TL, Kuhn LR (1932) The life history of Epibdella melleni MacCallum, 1927, a monogenetic trematode parasitic in marine fishes. Biol Bull 62:89-111

Kim KH, Choi ES (1998) Treatment of Microcotyle sebastis (Monogenea) on the gills of cultured rockfish (Sebastes schlegeli) with oral administration of mebendazole and bithionol. Aquaculture 167:115-121

Kim KH, Park SI, Jee BY (1998) Efficacy of oral administration of praziquiantel and mebendazole against Microcotyle sebastis (Monogenea) infestation of cultured rockfish (Sebastes schlegeli). Fish Pathol 33:467-471

Lester RJG (1972) Attachment of Gyrodactylus to Gasterosteus and host response. J Parasitol 58:717-722

Editorial responsibility: Wolfgang Körting,

Hannover, Germany
Lester RJG, Adams JR (1974) A simple model of a Gyrodactylus population. Int J Parasitol 4:497-506

Nigrelli RF, Breder CM Jr (1934) The susceptibility and immunity of certain marine fishes to Epibdella melleni, a monogenetic trematode. J Parasitol 20:259-269

Richards GR, Chubb JC (1996) Host response to initial and challenge infections, following treatment, of Gyrodactylus bullatarudis and G. turnbulli (Monogenea) on the guppy (Poecilia reticulata). Parasitol Res 82:242-247

Scott ME (1985) Experimental epidemiology of Gyrodactylus bullatarudis (Monogenea) on guppies (Poecilia reticulata): short and long term studies. In: Rollinson D, Anderson RM (eds) Ecology and genetics of host-parasite interactions. Academic Press, London, p 21-38

Scott ME, Robinson MA (1984) Challenge infections of Gyrodactylus bullatarudis (Monogenea) on guppies, Poecilia reticulata (Peters), following treatment. J Fish Biol 24: $581-586$

Secombes CJ (1994) Enhancement of fish phagocyte activity. Fish Shellfish Immunol 4:421-436

Vladimirov VL (1971) Immunity in fishes during dactylogyrosis. Parazitologiya 5:51-58 (in Russian)

Submitted: June 29, 1999; Accepted: October 11, 1999 Proofs received from author(s): January 29, 2000 